\title{
Why concern regarding privacy differs: The influence of age and (non-)participation on Facebook
}

\author{
Wouter M. P. Steijn ${ }^{1}$, Alexander P. Schouten ${ }^{2}$, Anton H. Vedder ${ }^{3}$ \\ ${ }^{1,2}$ Tilburg University, Tilburg, The Netherlands \\ ${ }^{3}$ Katholieke Universiteit Leuven, Leuven, Belgium
}

\begin{abstract}
Young people have obtained a reputation for caring less about their privacy due to their self-revealing presence on social media. Although one might easily be inclined to think that young people do not care about their privacy, an explanation for this could be that young people simply have a different idea of what privacy entails. This study aims to investigate the underlying mechanisms that may explain differences in privacy concerns between younger and older people and between users and non-users of social network sites (SNSs). 1.008 users of SNS and 712 non-users participated in the study with a stratified distribution over adolescents, young adults, and adults. The results show that the difference in perceived risk-benefit balance partly mediates the relationship between use or non-use of SNSs and concern. SNS users are less concerned because they perceive more benefits relative to risks. Concern regarding privacy between young and old was mediated by their differences in privacy conceptions. Older individuals were more likely to associate situations related to personal information with privacy. In turn, these individuals reported more concern regarding their privacy.
\end{abstract}

Keywords: Social media; privacy concerns; privacy conceptions; risk-benefit trade-off; adolescents; developmental differences

\section{Introduction}

Both users of social network sites (SNSs) and young people are often reported to be less concerned with privacy than non-users or older people (Acquisti \& Gross, 2006; Fox et al., 2000; Paine, Reips, Stieger, Joinson, \& Buchanan, 2007; Zukowski \& Brown, 2007). In fact, the two categories, being young and user of SNSs, often coincide as young people are the most intensive users of SNSs. As a result, young people obtained a reputation for caring less about their privacy due to their self-revealing presence on social media. Other research, however, showed that there is little difference in concern regarding privacy between young and old (e.g., Hoofnagle, King, Li, \& Turow, 2010; Madden \& Smith, 2010; Tufekci, 2012).

Despite these contradictory results, the underlying reasons for possible differences in privacy concern between younger and older people and users and nonusers have hardly been explored. However, understanding exactly why younger people report less concern can be useful, for example, for legislators and policy makers, as well as for internet entrepreneurs. For example, by helping them develop policy with which to better influence privacy behaviour of younger or older people, and can help internet entrepreneurs (e.g., SNSs owners) to better explain and manage the risks and benefits of SNS use. 
The reputation for being privacy care-free is generally attributed as a generational trait to young people who were born and increasingly live within a digital environment which makes the sharing of information easier (Nussbaum, 2007; Pafley \& Gasser, 2008). With our study we hope to show instead that young people differ in reported concern regarding privacy from older people at least for some part due to developmental reasons (Steijn \& Vedder, 2015). That is to say that some differences between young and old are due to the developmental age of the individuals, rather than the result of a generational difference caused by the impact of the emerging social media on young people's life.

Therefore, the goal of this paper is twofold. First, we investigate if there is a difference in concerns regarding privacy between younger and older adolescents and between users and nonusers of SNSs among a large representative sample of the Dutch population. Moreover, we will explore the underlying factors that could explain the differences in reported privacy concern between young and old and users and nonusers of SNSs. Specifically, we investigate whether differences in privacy conceptions --the idea of what privacy entails-- and risk-benefit assessment of using SNSs will explain the relationship between age and concern regarding privacy and SNS use and concern regarding privacy. More importantly, we expect to find different mediating paths between age and concern and use and concern, showing that young people differ from older people in concern for more reasons than them being users of SNSs.

\section{Theory and Hypotheses}

Currently, privacy has almost become the equivalent of data protection in public debate, while conceptually privacy is so much more. Vedder (2011) describes how, in the previous decade, privacy has been associated with a spatial (e.g., the privacy of one's home), relational (the privacy of intimate relationships), decisional (e.g., the privacy to make one's own decisions), and an informational aspect (e.g., the privacy of one's personal information). For this reason, we distinguish between privacy conceptions and concern regarding privacy in this paper. Privacy conceptions indicate an individual's idea of what privacy exactly entails (Steijn \& Vedder, 2015). Concern regarding privacy indicates how concerned the individual is with the status of their privacy (and can therefore be expected to depend on their privacy conception).

Below we explicate the two underlying factors that mediate the effect between age, use of SNSs and concern regarding privacy. We investigate the effect of two potential mediators on the relationship between age and (non-)users, and concern regarding privacy. Although various factors may affect the concern for privacy an individual holds, we will focus here on privacy conceptions and a risk-benefit trade-off that could both influence the differences between users and non-users of SNSs and between individuals of different age. However, before explaining the mediators, we must first pose that there is a direct effect between individual's use of SNSs, and the individual's age and concern regarding privacy. This would be a replication of findings from earlier studies which showed users of SNSs report less concern compared to non-users (Acquisti \& Gross, 2006), and that younger people report less concern regarding privacy compared to older people (Fox et al., 2000; Paine et al., 2007; Zukowski \& Brown, 2007). The first two hypotheses therefore state:

\section{H1: Users of SNSs will report less concern regarding their privacy compared to non-users}

H2: Younger individuals will report less concern regarding their privacy compared to older individuals.

\section{Risk-Benefit Trade-0ff}

The use of SNSs has been linked to many personal and social benefits, such as SNSs provision of possibilities to develop the identity development, social support, and relationship formation (Ellison, Steinfield, \& Lampe, 2007; Grimmelmann, 2009; Kim, \& Lee, 2011; Lee, Noh, \& Koo, 2013; Steijn \& Schouten, 2013). In order to obtain the benefits that SNSs can offer, individuals need to share information and in so doing they will hence make themselves vulnerable to privacy risks as a consequence of sharing personal information on a (semi-)public forum. Privacy risks consist among others of becoming subjected to discriminatory treatment as a result of profiling or data mining (Andrews, 2012), information becoming available for individuals for whom it was not intended, such as employers (Levy, 2009) or teachers (O'Dell, 2011), or identity theft (Noda, 2009). This latter 
phenomenon, the presence of multiple audiences in a single medium, is also known as 'context collapse' (Marwick \& boyd, 2011).

A risk-benefit trade-off is therefore likely a part of individual's decision to make use of SNSs and share information. Individuals who have higher expectations of benefits will be more likely to disclose more or more intimate information on their profile than individuals who consider the risks more likely to occur (Beldad, de Jong, \& Steehouder, 2011). ${ }^{1}$ Non-users of SNSs would then most likely be individuals who generally consider risks to be more probable compared to benefits. This idea is also known as the privacy calculus (Dinev \& Hart, 2006). The privacy calculus model describes how individuals balance their privacy concerns against their anticipation of benefits in their decision to disclose information. Trust is identified in this model as a facilitating factor. Several studies examined the privacy calculus previously such as Xu, Michael, and Chen (2013) who studied the privacy calculus in combination with the theory of planned behaviour, Krasnova, Veltri, and Günther (2012) who examined the role of culture on the privacy calculus, and Krasnova, Spiekermann, Koroleva, and Hildebrand (2010) who found trust and perceived control to be mitigating factors for privacy risks. Here we build on these studies by examining the mediating role of expected risks and benefits from the sharing of information on the relationship between relationship between of age and use or non-use with concern regarding privacy.

Perceived vulnerabilities to online risks are related to concern regarding privacy (Mohamed \& Ahmed, 2012; Youn, 2009; Youn \& Hall, 2008). Thus, the risk-benefit trade-off could potentially distinguish users from nonusers, and explain why users report less concern compared to non-users. In other words, the users of SNSs are likely to be individuals who generally consider more benefits than risks likely to occur as a result of sharing information on SNSs, who in turn are expected to report less concern (Beldad et al., 2011; Mohamed \& Ahmed, 2012; Youn, 2009; Youn \& Hall, 2008). In this paper we will define the expectation of more benefits relative to risks as a positive risk-benefit trade-off. We therefore pose the following hypothesis:

H3: The relationship between SNS use and concern regarding privacy is mediated by a positive riskbenefit trade-off.

Research has also shown that the adolescent brain is insufficiently physically mature yet for proper risk decisionmaking and that adolescents are more focussed on rewards rather than risks, especially in the presence of peers (Furby \& Beyth-Marom, 1992; O'Brien, Albert, Chein, \& Steinberg, 2011; Steinberg, 2008). Alternatively, in their study to comparative optimism Baek, Kim, and Bae report that young people are likely to overestimate their privacy risks (2014). Moreover, most of the social benefits that can be obtained through SNSs are particularly relevant to young people. Developing an identity and relationship formation to build social capital are important tasks during adolescence (Boneva, Quinn, Kraut, Kiesler, \& Shklovski, 2006; boyd, 2008; Bukatko, 2008; Marwick, Diaz, \& Palfrey, 2010; Mesch \& Talmud, 2010; Peter \& Valkenburg, 2011; Steijn, 2014a). This would suggest that young people have a differing risk-benefit trade-off compared to older people with regard to SNSs, i.e., one more focussed on the benefits, which could, in turn, lead to less concern among young people.

H4: The relationship between age and concern regarding privacy is mediated by a positive riskbenefit trade-off.

\section{Privacy Conceptions}

The second underlying factor that could affect an individual's concern regarding privacy would be their idea of what exactly constitutes privacy, that is, their privacy conception (Steijn \& Vedder, 2015). In view of the current developments taking place on the internet, and the popularity of SNSs, the privacy debate has focused primarily on personal information. However, not all individuals will necessarily hold a privacy conception that focusses solely on personal information (Steijn \& Vedder, 2015). In fact, we argue that this may present an essential difference in the privacy conceptions that young people and old people hold.

Steijn \& Vedder (2015) investigated the privacy conception of adolescents (12- to 19-year-olds), young adults (20to 30-year olds), and adults (31-years-old and older). They asked respondents which situations, related to autonomy, relationships, personal space, or personal information, they associated with privacy in order to determine the privacy conceptions. Two important differences were reported in that study. Relatively more 
adolescents associated privacy with situations involving relationships, for example being able to be alone with a partner or friend, whereas relatively more adults associated privacy with those situations that involve personal information, for example, the government collecting data. Here we will focus primarily on the personal information aspect of privacy since this aspect had a stronger relationship with concern regarding privacy while the relational aspect of privacy was only marginally related to concern (Steijn \& Vedder, 2015).

These differences were explained by pointing out that early in life individuals have different concerns when compared to individuals in latter developmental life phases (Steijn \& Vedder, 2015). For adolescents, being able to hang out with friends and to develop relationships is an important developmental goal (Peter \& Valkenburg, 2011). Their main concern is to be able to do so away from the scrutiny of parental supervision (boyd \& Marwick, 2011). As individuals grow older and leave the parental house to become home owners and earn a living, their societal position changes. Threats of data mining and profiling by bankers, authorities, and future employers become more prominent in later age. These parties arguably play a smaller role in the lives of young people who instead are pre-occupied with their relational privacy in the parental homes. Young people are not completely blind to these informational threats however, and studies have shown that they are more likely to use privacy measures as their concerns increase (Mohammed \& Ahmad, 2012).

Here we will build on these analyses to show that the decreased focus on the privacy conception on personal informational explains why younger people report less concern regarding their privacy. Moreover, while privacy conceptions vary as a function of age, we expect them to be unrelated to SNS use as privacy conceptions are the result of a difference in developmental stage of adolescents and not a function of SNS use. We therefore post the last hypothesis:

$\mathrm{H} 5$ : The relationship between age and concern regarding privacy is mediated by privacy conception of personal informational.

\section{Method}

\section{Sample and Procedure}

Data were collected from July 19 until August 4, 2011 by the research institute TNS-NIPO (http://www.tnsnipo.com), who recruited the sample from their representative sample pool of the Dutch population. Data collection was part of a large-scale study into the uses of SNSs among different age groups and privacy regulation (Steijn, 2014b). Respondents were recruited through a stratified sampling procedure based on age, including adolescents (12- to 19-year-olds), young adults (20- to 30-year olds), and adults (31-years-old and older), and the fact whether or not they made use of a SNS. Respondents gave their consent to participate in the research survey (parents provided consent for individuals younger than 18 years of age). From the 3,170 respondents approached for this survey, 1,720 respondents completed the questionnaire. Altogether, 1.008 respondents made use of a SNS and 712 did not. Six respondents were removed from the sample as they explicitly stated having created their profile merely for a different purpose (e.g., as requirement for using another site). Table 1 provides the details of the respondents' age, gender and distribution across the six categories. We distinguish between adolescents, young adults and adults in the table below to show that all three developmental age groups are represented. In the analysis age will be included as a continuous variable.

\section{Measures}

Concern regarding privacy. In order to assess how concerned individuals are with their privacy, they were asked whether they were concerned about their privacy, think their privacy is important, feel they have too little privacy, and consider the internet as a threat to their privacy. Ratings were made on a 4-point Likert scale from completely disagree (1) to completely agree (4). Factor Analysis confirmed acceptable loadings for each item (.85, $.76, .33, .55$, respectively), the 4 items were combined into a single scale $(a=.72$, composite reliability $=.73)$. See Table 2 for the mean and standard deviation of the scale. 
Table 1. Sample's Distribution (1a), Mean Age (1b), and Gender (1c).

\begin{tabular}{|c|c|c|c|c|}
\hline \multicolumn{5}{|c|}{ 1a. Distribution (\% of total sample) } \\
\hline & Adolescents & Young Adults & Adults & Total \\
\hline Non-use & $219(12.8 \%)$ & $174(10.1 \%)$ & $319(18.6 \%)$ & $712(41.5 \%)$ \\
\hline Use & $372(21.7 \%)$ & $277(16.2 \%)$ & $353(20.6 \%)$ & $1,002(58.5 \%)$ \\
\hline Total & $591(34.5 \%)$ & $451(26.3 \%)$ & $672(39.2 \%)$ & $1,714(100 \%)$ \\
\hline \multicolumn{5}{|l|}{ 1b. Age } \\
\hline & Adolescents & Young Adults & Adults & Total \\
\hline Non-use & $14.57(2.16)$ & $25.83(3.25)$ & $50.58(13.66)$ & $33.46(18.52)$ \\
\hline Use & $14.60(2.16)$ & $25.55(3.10)$ & $46.22(12.12)$ & $28.77(15.52)$ \\
\hline Total & $14.59(2.16)$ & $25.66(3.16)$ & $48.29(13.05)$ & $30.71(16.99)$ \\
\hline \multicolumn{5}{|c|}{ 1c. Gender (\% male of distribution) } \\
\hline & Adolescents & Young Adults & Adults & Total \\
\hline Non-use & $138(63.0 \%)$ & $83(47.7 \%)$ & $141(44.2 \%)$ & $362(50.8 \%)$ \\
\hline Use & 175 (47.0\%) & 80 (28.9\%) & 145 (41.1\%) & 400 (39.9\%) \\
\hline Total & $313(53.0 \%)$ & $163(36.1 \%)$ & $286(42.6 \%)$ & $762(44.5 \%)$ \\
\hline
\end{tabular}

Note: Age provides means with standard deviation in brackets.

Privacy conception. Respondents' privacy conceptions were assessed with two privacy-related situations. Respondents were asked which of the situations they associated with privacy by asking simple yes-no questions. The situations were based on the four factors of privacy identified by Vedder (2011): relationships, personal information, personal space, and autonomy. In this study, we focus on the situations involving personal information since it has the strongest relationship with concern regarding privacy (Steijn \& Vedder, 2015) of all four factors. Privacy conceptions related to personal information can therefore be expected to have the strongest relationship with reporting concern for privacy. These situations concerned data collection (the government collecting information about the respondent) and information sharing (putting information on the internet). The scores for these items were added together to create a single privacy conception (personal information) scale with a range of 0 to 2 (situations associated with privacy). See Table 2 for the mean and standard deviation of the scale.

Risk and benefit perception. Respondents were presented with a list of 16 potential outcomes from sharing information on SNSs. Respondents were asked to indicate for each situation how likely they considered the outcome to be. The outcomes could be differentiated into 9 potential risks and 7 potential benefits. The risks were as follows: a fight in the family, losing money, being bullied, reputation being defamed, having undesirable contact with a stranger, getting into contact with someone you are trying to avoid, getting into a fight with a friend, identity being stolen, and a boss or teacher discovering embarrassing information about the respondent. The benefits were: getting a job, a boss or teacher discovering positive information about the respondent, becoming more popular, staying in touch with friends who had moved, working out an argument, feeling happy, and renewing contact with a lost friend. Responses were measured on a 4-point-Likert scale ranging from 1 (very likely) to 4 (very unlikely) with a 'don't know' option (5).

To assess the risk benefit trade-off, we created a risk-benefit balance scale based on the number of risks and benefits respondents considered likely to occur (or not). First, a risk perception scale and a benefit perception scale was created by counting the number of situations they considered 'likely' or 'very likely'. Respondents who had reported 'don't know' were counted as not believing the situation likely. As a result, two continuous scales were obtained ranging from 0 to $9(M=2.62, S D=2.90)$ for risk perception, and ranging from 0 to $7(M=2.22, S D=1.96)$ for benefit perception. The second step to obtain the risk-benefit balance scale was to subtract the risk perception scale from the benefit perception scale. As a result, we obtained an interpretable continuous scale ranging from - 
9 to $7(M=-0.40, S D=2.28)$. Positive scores indicate the respondent considered relatively more benefits likely to occur, whereas negative scores indicate the respondents considers relatively more risks likely to occur as the result of sharing information.

\section{Results}

Table 2 provides the mean, standard deviation, and correlations between the variables. We analysed the results with Structural Equation Modelling using AMOS 23.0. This method allows for the analysis of mediation models with multiple independent and mediator variables. Here, use and age were entered as independent variables, privacy conception (personal information) and risk-benefit balance, as mediation variables, and concern regarding privacy as dependent variable. All variables were first created in SPSS and were entered into AMOS as manifest variables. To assess the goodness of fit of the model, we report multiple measures. First, we report the $\chi^{2}$-square and the $\chi^{2}$-square/df ratio. A model with good fit should have a low $\chi^{2}$-square/df ratio and ideally a nonsignificant $\chi^{2}$-square (Kline, 2005). We also report the Root Mean Square Error of Approximation (RMSEA), of which a value below .05 is considered a good fit (Diamantopoulos \& Siguaw, 2000; Schermelleh-Engel, Moosbrugger \& Müller, 2003). The final commonly reported fit measure is the Comparative Fit Index (CFI). A value above .95 is generally considered a good fit and a value above .90 an 'acceptable' fit (Kelloway, 1998).

Table 2. Means, Standard Deviations, and Correlations.

\begin{tabular}{lllllllll}
\hline & $\boldsymbol{M}$ & SD & $\mathbf{1}$ & $\mathbf{2}$ & $\mathbf{3}$ & $\mathbf{4}$ & $\mathbf{5}$ & $\mathbf{6}$ \\
\hline 1. Concern regarding privacy & 0.74 & 0.57 & & & & & & \\
2. Age & 30.71 & 16.99 & $.13^{* * *}$ & & & & & \\
3. Use & - & - & $-.16^{* * *}$ & $-.14^{* * *}$ & & & & \\
4. Privacy Conception & 1.32 & 0.74 & $.19^{* * *}$ & $.08^{* *}$ & -.01 & & & \\
5. Risk perception & 2.62 & 2.90 & $.21^{* * *}$ & $-.06^{*}$ & $-.24^{* * *}$ & $.13^{* * *}$ & & \\
6. Benefit perception & 2.22 & 1.96 & .02 & $-.13^{* * *}$ & $.12^{* * *}$ & $.11^{* * *}$ & $.62^{* * *}$ & \\
7. Risk Benefit balance & -0.40 & 2.28 & $-.25^{* * *}$ & -.03 & $.41^{* *}$ & $-.07^{* *}$ & $-.74^{* * *}$ & $.07^{* *}$ \\
\hline
\end{tabular}

Note: Correlations significant at ${ }^{*} p<.05 ;{ }^{* \star} p<.01, * \star \star p<.001$

We first tested the model including all relationships between the independents, mediating and dependent variables. The fit of the model could not be assessed because no degrees of freedom were left to assess the fit of the model. However, maximum likelihood estimates indicated that the relationships between use and privacy conception and between age and risk-benefit trade-off were not significant ( $\beta^{\prime} s<|.02|$ and $p^{\prime} s>.3$ ). Therefore, we removed these paths from the model, which yielded the model as depicted in Figure 1. The model exhibited good fit, $\chi^{2}(2)=1.09, p=.058, \chi^{2} / \mathrm{df}=0.54, \mathrm{CFI}>0.99$, RMSEA $=.001$. Moreover, modification indices showed no additional paths could be drawn. Therefore, we maintained this model as our final model.

Results show a significant direct effect of age on concern regarding privacy, $\beta=.10, p<.001$, and of use on concern regarding privacy, $\beta=-.06, p=.022$. Moreover, the total effect of age on concern regarding privacy was .12 and the total effect of use on concern regarding privacy was -.14 , thus confirming both hypothesis 1 and 2 .

Hypothesis 3 posed that the relationship between SNS use and concern regarding privacy is mediated by a riskbenefit trade-off, while hypothesis 4 posed that the relationship between age and concern regarding privacy would also be mediated by a risk-benefit trade-off. As stated above, the relationship between age and riskbenefit trade-off was not significant, thereby disconfirming $\mathrm{H} 4$. $\mathrm{H} 3$ was confirmed, the relationship between use and risk-benefit trade-off is significant, $\beta=.41, p<.001$, as is the relationship between risk-benefit trade-off and concern regarding privacy, $\beta=-.21, p<.001$. The indirect effect from use on concern regarding privacy was -.09 . 


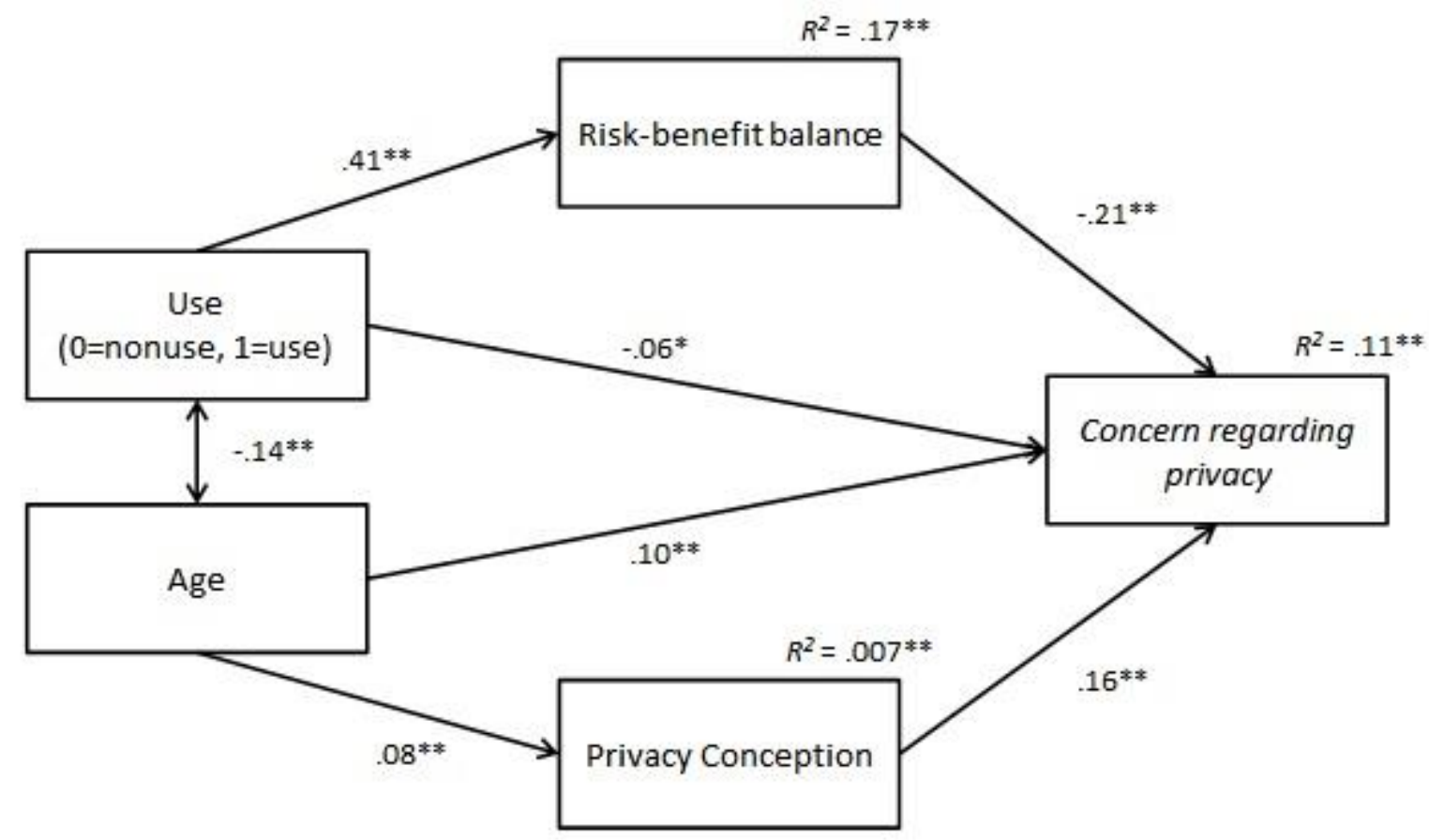

Figure 1. Final SEM model showing the relationships between variables. Coefficients are standardized betas and are significant at least at $* p<.05$ and $* * p<.001$. The correlation between disturbance terms (i.e., of the riskbenefit balance and privacy conception) is .08 but not shown for clarity reasons.

The last hypothesis (H5) posed that the relationship between age and concern regarding privacy would be mediated by privacy conceptions. This hypothesis was supported as well. First, the relationship between age and privacy conceptions was significant, $\beta=.08, p<.001$. Second, the relationship between privacy conceptions and concerns regarding privacy was significant, $\beta=.16, p<.001$. The total indirect effect from age on concern was .01. In all, risk-benefit trade-off partially mediated the relationship between SNS use and concern regarding privacy, while privacy conceptions partially mediated the relationship between age and concern regarding privacy.

\section{Discussion}

This article set out to investigate the effects of a risk-benefit trade-off and privacy conceptions as mediators of the relationship between participation in SNSs and age, and concern regarding privacy. The results show that the relationship between participation in SNSs and concern was mediated by a risk-benefit trade-off. The relationship between age and concern was however mediated by privacy conceptions. This distinction in mediating factors suggest that age and participation in SNSs (or not) should be considered as separate factors when investigating the privacy appreciation of, for example, young people.

A likely explanation for the popularity of SNSs could be that many people consider the benefits of participating and sharing information on such sites to be more probable than the (privacy) risks. The results presented here support this idea as users were found to consider more benefits likely, but fewer risks likely to occur compared to non-users. As a result, users generally have a positive risk-benefit balance concerning the sharing of personal information on SNSs, whereas non-users on average have a negative risk-benefit balance. We showed that respondents who perceive relatively more benefits than risks likely to occur also reported less concern regarding privacy. This finding is in agreement with previous studies that showed that concern regarding privacy is related to the perceived vulnerabilities to online risks (Mohamed \& Ahmed, 2012; Youn, 2009). Furthermore, we showed that the differences in risk-benefit balance partly mediates the relationship between use or non-use of SNSs and concern. In other words, the lower concern regarding privacy reported by SNS users can be partially explained by the more positive outlook on the likelihood of both benefits and risks as the result of sharing information on SNSs. 
The differences in concern regarding privacy between young and old were instead partially mediated by differences in privacy conception. We showed that older individuals were more likely to associate situations related to personal information. In turn these individuals reported more concern regarding their privacy. The internet primarily poses a privacy risk in relation to personal information in the form of data mining, bankers, future employers, and authorities. However, only once individuals leave the parental home and start working, do bankers, future employers, and authorities start to play prominent roles in their lives. For younger people still living in their parental homes these risks may still appear more abstract. The lower concern regarding privacy reported by young people can partially be explained by the fact that personal informational (and the associated risks) is a less prominent aspect of their privacy conception.

This result shows that observed differences in reported concern regarding privacy could be an artefact of the ambiguity surrounding the term privacy. Only recently has privacy almost become the equivalent of data protection, while privacy conceptually is so much more. Besides informational privacy, privacy also includes spatial, autonomy and relational aspects (Vedder, 2011). Reported concern regarding privacy can only really be interpreted once it is made clear what type of privacy the respondent is talking about.

The results presented here also suggest that the differences observed in privacy conception and concern regarding privacy between young and old are not necessarily also related to the use of social media. Users and non-users of SNSs also differ in concern regarding their privacy, but did not have different privacy conceptions when we controlled for age. Often, no distinction is made between the fact that an individual is young and the fact that an individual is a user of SNSs when discussing their privacy attitudes. The results here show that we should: users of SNSs differ from non-users in reported concern regarding their privacy for other reasons than young people from older people. As a consequence, these results suggest that the differences in concern regarding privacy between young and old may always have existed and are of a developmental nature. Social media may, therefore, have served to make these differences become more apparent, rather than having actually caused generational differences in concern between young and old.

This is not to say that the introduction of social media will have no generational influences. However, for researchers it is important to make a clear distinction between differences we observe that are of a generational nature (due to the introduction of social media in everyday life) and differences that may be of a different nature and which have only become more apparent now a great part of social interaction takes place online. The results here make the latter view more plausible.

This paper draws on data collected in 2011 and could therefore be considered dated. However, we believe that the findings reported, even if originating from 5 years ago, are still relevant for the current day and age. They represent potentially stable developmental differences which would be resistant to the rapid technological advancements and developments occurring in society. In other words, even though Facebook may be less relevant today as it was five years ago, the reported differences between young and old are relevant for understanding online behaviour in general.

This study represents cross-sectional and correlational data. Therefore, no evidence for causality is provided. We argue throughout the paper that a negative risk-benefit trade-off leads to more concern regarding privacy. However, it could also be argued that individuals with higher concern for their privacy are more likely to consider risks more likely to occur. What we present here is what we consider most likely, but the provided results should not be taken as evidence for the proposed causality.

The presented results help understand why young people may report less concern while being more active at social media at the same time. Personal information features less prominent in their conception of privacy. Similarly, Dienlin and Trepte (2015) showed that distinguishing between privacy concerns, privacy attitudes, and intentions provided a fruitful way of explaining why people continue sharing information on SNSs regardless of privacy concerns. Here we only looked at the relationship between privacy conceptions and reported concern. Future studies may want to explore how different privacy conceptions relate to attitudes and intentions as well.

Taking these limitations into account, the findings presented here still contribute to the privacy discussion. The reported differences in the conception of privacy young and old hold has important implications when seeking 
effective ways to regulate online privacy. Policy makers should realise that regulations which might be effective for adults, might not be effective for adolescents. In addition, just because informational privacy is less prominent in young people's live does not mean that their informational privacy is not at risk. Keeping an adultoriented perspective on privacy and assuming that the lower concern is (only) related to adolescents' exposure to SNSs is likely to result in ineffective regulation.

\section{Note}

1. Please note that we focus here solely on the likelihood of the risk occurring, while risk definitions usually combine the probability with the severity of a certain negative outcome.

\section{References}

Acquisti, A., \& Gross, R. (2006). Imagined communities: awareness, information sharing, and privacy on the Facebook. 6th Workshop on Privacy Enhancing Technologies. Cambridge, UK.

Andrews, L. (2012, February 4). Facebook is using you. The New York Times. Retrieved from http://www.nytimes.com

Baek, Y. M., Kim, E.-m., \& Bae, Y. (2014). My privacy is okay, but theirs is endangered: Why comparative optimism matters in online privacy concerns. Computers in Human Behavior, 31, 48-56.

http://dx.doi.org/10.1016/j.chb.2013.10.010

Beldad, A., de Jong, M., \& Steehouder, M. (2011). A comprehensive theoretical framework for personal information-related behaviors on the Internet. The Information Society, 27, 220-232.

http://dx.doi.org/10.1080/01972243.2011.583802

Boneva, B.S., Quinn, A., Kraut, R.E., Kiesler, S., \& Shklovski, I. (2006). Teenage communication in the instant messaging era. In R. Kraut, M. Brynin, \& S. Kiesler (Eds.), Computers, phones, and the Internet: Domesticating information technology (pp. 201-218). Oxford, New York: Oxford University Press.

boyd, d.m. (2008). Taken out of context: American teen sociality in networked publics publics [Doctoral dissertation, Berkeley, University of California]. Retrieved from http://www.danah.org/papers/TakenOutOfContext.pdf

boyd, d.m., \& Marwick, A. E. (2011). Social privacy in networked publics: teens' attitudes, practices, and strategies. A decade in internet time: symposium on the dynamics of the internet and society. Retrieved from http://ssrn.com/abstract=1925128

Bukatko, D. (2008) Child and adolescent development. Boston: Houghton Mifflin.

Diamantopoulos, A., \& Siguaw, J. A. (2000). Introducing LISREL. A guide for the uninitiated. London: Sage.

Dienlin, T., \& Trepte, S. (2015). Is the privacy paradox a relic of the past? An in-depth analysis of privacy attitudes and privacy behaviors. European Journal of Social Psychology, 45, 285-297. http://dx.doi.org/10.1002/ejsp.2049

Dinev, T. \& Hart, P. (2006). An extended privacy calculus model for E-commerce transactions. Information Systems Research, 17(1), 61-80. http://dx.doi.org/10.1287/isre.1060.0080 
Ellison, N.B., Steinfield, C., \& Lampe, C. (2007). The benefits of Facebook "friends": social capital and college students' use of online social network sites. Journal of Computer-Mediated Communication, 12, 1143-1168. http://dx.doi.org/10.1111/j.1083-6101.2007.00367.x

Fox, S., Rainie, L., Horrigan, J., Lenhart, A., Spooner, T., \& Carter, C. (2000). Trust and privacy online: Why Americans want to rewrite rules. The Pew Internet \& American Life Project. Retrieved from http://www.pewinternet.org/ /media/Files/Reports/2000/PIP_Trust_Privacy_Report.pdf.pdf

Furby, L., \& Beyth-Marom, R. (1992). Risk taking in adolescence: A decision-making perspective. Developmental Review, 12, 1-44. http://dx.doi.org/10.1016/0273-2297(92)90002-j

Grimmelmann, J. (2009). Saving Facebook. lowa Law Review, 94, 1137-1206.

Hayes, A. F., \& Preacher, K., J. (2014). Statistical mediation analysis with a multicategorical independent variable. British Journal of Mathematical and Statistical Psychology, 67, 451-470. http://dx.doi.org/10.1111/bmsp.12028

Hoofnagle, C., King, J., Li, S., \& Turow, T. (2010). How different are young adults from older adults when it comes to information privacy attitudes \& policies? Retrieved from http://ssrn.com/abstract=1589864

Kelloway, E. K. (1998). Using Lisrel for structural equation modeling. A researcher's guide. London: Sage.

Kim, J., \& Lee, J.-E.R. (2011). The Facebook paths to happiness: Effects of the number of Facebook friends and self-presentation on subjective well-being. Cyberpsychology, Behavior, and Social Networking, 14, 359-364.

http://dx.doi.org/10.1089/cyber.2010.0374

Kline, R. B. (2005). Principles and practice of structural equation modeling. New York: Guilford Press.

Krasnova, H., Spiekermann, S., Koroleva, K., \& Hildebrand, T. (2010). Online social networks: Why we disclose. Journal of Information Technology, 25, 109-125. http://dx.doi.org/10.1057/jit.2010.6

Krasnova, H., Veltri, N. F., \& Günther, O. (2012). Self-disclosure and privacy calculus on social networking sites: The role of culture. Business \& Information Systems Engineering, 4, 127-135. http://dx.doi.org/10.1007/s12599-0120216-6

Lee, K.-T., Noh, M.-J., \& Koo, D.-M. (2013). Lonely people are no longer lonely on social network sites: the mediating role of self-disclosure and social support. Cyberpsychology, Behavior, and Social Networking, 16, 413418. http://dx.doi.org/10.1089/cyber.2012.0553

Levy, A. (2009. February 26). Teenage office worker sacked for moaning on Facebook about her 'totally boring' job. Daily Mail. Retrieved from http://www.dailymail.co.uk/news/article-1155971/Teenage-office-worker-sackedmoaning-Facebook-totally-boring-job.html

Madden, M., \& Smith, A. (2010). Reputation management and social media: How people monitor their identity and search for others online. Pew Internet \& American Life Project report. Retrieved from http://www.pewinternet.org/reports/2010/reputation-management.aspx

Marwick, A. E., \& boyd, d. m. (2011). I tweet honestly, I tweet passionately: Twitter users, context collapse, and the imagined audience. New Media \& Society, 13, 114-133. http://dx.doi.org/10.1177/1461444810365313

Marwick, A.E., Diaz, D.M., \& Palfrey, J. (2010). Youth, privacy and reputation. Retrieved from http://ssrn.com/abstract=1588163

Mesch, G.S., \& Talmud, I. (2010). Wired Youth. The social world of adolescence in the informational age. New York: Routledge. 
Mohamed, N., \& Ahmad, I. H. (2012). Information privacy concerns, antecedents and privacy measure use in social networking sites: Evidence from Malaysia. Computers in Human Behavior, 28, 2366-2375.

http://dx.doi.org/10.1016/j.chb.2012.07.008

Noda, T.S. (2009, December 12). Facebook still a hotbed of identity theft, study claims. PCWorld. Retrieved from http://www.pcworld.com

Nussbaum, E. (2007, February 12). The kids, the internet, and the end of privacy: the greatest generation gap since Rock and Roll. New York. Retrieved from http://nymag.com/news/features/27341/

O'Brien, L., Albert, D., Chein, J., \& Steinberg, L. (2011) Adolescents prefer more immediate rewards when in presence of their peers. Journal of Research on Adolescence, 21, 747-753. http://dx.doi.org/10.1111/j.15327795.2011.00738.x

O'Dell, J. (2011, February 1). Student suspended for calling teacher fat on Facebook. Mashable. Retrieved from http://mashable.com/2011/02/01/facebook-free-speech-high-school/

Palfrey, J., \& Gasser, U. (2008). Born digital. New York: Basic Books.

Paine, C., Reips, U-D., Stieger, S., Joinson, A., \& Buchanan, T. (2007). Internet users' perception of 'privacy concerns' and 'privacy actions'. Human-Computer Studies, 65, 526-536.

http://dx.doi.org/10.1016/j.ijhcs.2006.12.001

Peter, J., \& Valkenburg, P. (2011). Adolescents' online privacy: Toward a developmental perspective. In S. Trepte \& L. Reinecke (Eds.), Privacy online (pp. 221-234). Heidelberg: Springer.

Schermelleh-Engel, K., Moosbrugger, H., \& Müller, H. (2003). Evaluating the fit of structural equation models: Tests of significance and descriptive goodness-of-fit measures. Methods of Psychological Research Online, 8, 23-74.

Steijn, W. M. P. (2014a). A developmental perspective regarding the behaviour of adolescents, young adults, and adults on social network sites. Cyberpsychology: Journal of Psychosocial Research on Cyberspace, 8(2), article 5. http://dx.doi.org/10.5817/CP2014-2-5

Steijn, W. M. P. (2014b). Developing a sense of privacy: An investigation of privacy and the differences between young and old in the context of social network sites [Doctoral dissertation]. Tilburg: Tilburg University. Retrieved from https://pure.uvt.nl/portal/en/publications/developing-a-sense-of-privacy(6a060916-8be2-463e-b5fe392322a95ad7).html

Steijn, W. M. P., \& Schouten, A. P. (2013). Information sharing and relationships on social network sites. Cyberpsychology, Behavior, \& Social Networking, 16, 582-587. http://dx.doi.org/10.1089/cyber.2012.0392

Steijn, W. M. P., \& Vedder, A. (2015). Privacy under construction: A developmental perspective on privacy perception. Science, Technology, \& Human Values, 40, 615-637.

Steinberg L. (2008). Adolescence (8th edition). Boston: MacGraw Hill.

Tufekci, Z. (2012). Facebook, youth and privacy in networked publics. In Proceedings of the Sixth International AAAI Conference on Weblogs and Social Media (pp. 338-345).

Vedder, A. (2011). Privacy 3.0. In S. van der Hof \& M. Groothuis (Eds.), Innovating Government (pp. 17-28). New York/Berlin/The Hague: Springer/Asser Press.

Wolak, J., Mitchell, K.J., \& Finkelhor, D. (2002). Close online relationships in a national sample of adolescents. Adolescence, 37, 441-456. 
Xu, F., Michael, K., \& Chen, X. (2013). Factors affecting privacy disclosure on social network sites: An integrated model. Electronic Commerce Research, 13, 151-168. http://dx.doi.org/10.1007/s10660-013-9111-6

Youn, S. (2009). Determinants of online privacy concern and its influence on privacy protection behaviors among young adolescents. The Journal of Consumer Affairs, 43, 389-418. http://dx.doi.org/10.1111/j.1745-

6606.2009.01146.x

Youn, S., \& Hall, K. (2008). Gender and online privacy among teens: risk perception, privacy concerns, and protection behaviors. CyberPsychology \& Behavior, 11, 763-765. http://dx.doi.org/10.1089/cpb.2007.0240

Zukowski, T., \& Brown, I. (2007). Examining the influence of demographic factors on internet users' information privacy concerns. In Proceedings of SAICSIT conference (pp. 197-204). New York: ACM.

\section{Correspondence to:}

Dr. Wouter M.P. Steijn

Tilburg University

Koningsveldland 9

2635 MM Den Hoorn

The Netherlands

Email: wsteijn(at)gmail.com

\section{About authors}

Wouter Steijn obtained his masters degree in Psychology at Leiden University. In 2014 he successfully defended his doctoral thesis at Tilburg University. In his dissertation he focused on a developmental explanation for the differences in privacy perception between young and old.

Alexander Schouten is an assistant professor of Digital Media at the Tilburg center for Cognition and Communication. His research interests focus on online impression formation and social attraction.

Anton Vedder is a full-time professor of Law and IT at the KU Leuven Centre for IT and IP Law. He is also affiliated to Tilburg University. His research and teaching mainly focus on ethics and the regulation of innovative technologies. 